\title{
A CASE-BASED REASONING APPROACH TO ENHANCE WEB-BASED TRAINING ON INTERNET MARKETING
}

\author{
Duan, Y. ${ }^{1}$, Burrell, P. ${ }^{2}$, Mullins, R. ${ }^{3}$ and Jin, H. ${ }^{3}$ \\ 1-University of Luton, UK, 2 - South Bank University,UK, -University of Wales Lampeter, UK,
}

\begin{abstract}
Lack of knowledge and skills among small business managers has been well recognised, but how to effectively support small business managers in their knowledge acquisition and decision making with emerging information and communication technologies is still a challenge. This paper describes an application attempt to develop an intelligent web-based training system for SMEs to aid their learning and decision-making regarding the use of the Internet as a new marketing medium. Based on the training needs analysis carried out by a EU-funded research project TRIMAR, a case-based reasoning (CBR) approach is adopted as an effective tool to help small business managers to learn and to make better decisions. Over seventy small business Internet marketing cases were collected and processed. They form a case base for CBR in the system. The initial feedback from users proves using case base reasoning approach is effective, but the quality and the comprehensiveness of case base are key factors for the usefulness of the system.
\end{abstract}

Key words: Case-based reasoning, case based learning, intelligent web-based training, Internet Marketing, SMEs.

\section{INTRODUCTION}

Development of information and communications technologies has resulted in the emergence of new directions in marketing policies and activities. The Internet has become an attractive tool of marketing (Chaffey, 2002; Coupey, 2001; Dann, 2001). Decision makers from Small and Medium Enterprises (SMEs) ${ }^{1}$ have to face difficulties while implementing and utilising the Internet marketing. The lack of knowledge and skills that 
are necessary to introduce and carry out Internet marketing is one of barriers contributing to the difficulties. The situation was reflected in a survey conducted within EU funded pilot project TRIMAR ${ }^{2}$. TRIMAR attempts to contribute to the wider debate on the content and style of training most suitable to small businesses. It aims to identify the training needs of the small businesses for Internet Marketing at a pan-European level and to seek the most effective way to address the training and support needs with webbased systems. The findings from project Pan-European survey reveals the necessity to provide decision makers with up to date knowledge on Internet marketing and to develop skills that are indispensable. This paper reports the application attempt to address the training and decision support needs using Case Based Reasoning approach.

\section{INTERNET MARKETING CHALLENGES IN SMES}

The Internet provides exciting new opportunities for SMEs to extend their business to the global market place. However, introducing Internet marketing into SMEs and combining both off-line and on-line marketing campaigns is not an easy process. This process requires that decision-makers and marketing specialists acquire new skills.

Surveys and focus groups conducted at the University of Luton, with SMEs revealed that:

- SMEs are not equipped with necessary expertise to deal with culturebased market differences such as consumer and market characteristics.

- They do not have experience of world market characteristics and do not know how to adapt their companies to the converging global market place in terms of products, promotion and distribution.

- They have no knowledge of how other SMEs are operating on the Internet and which Internet Marketing models they are adopting.

The managers would like to learn from the successful experiences of other SMEs and adopt best practices identified from Internet marketing case studies within their sector.

To further investigate the training and decision support needs on adopting the Internet marketing in SMEs. TRIAMR carried out questionnaire surveys in five countries in Europe (UK, Germany, Poland, Slovak Republic and Portugal). The surveys involved 190 enterprises. They

2 TRIMAR, i.e. On-Line Intelligent Training System for Internet Marketing by SMEs (UK/00/B/F/PP/129_110), is funded by the European Commission's Leonardo Da Vinci programme. 
of Internet as a marketing tool. More than half of respondents evaluated their level of Internet marketing knowledge and skills as low and insufficient. Most respondents believed that lack of knowledge and inhouse expertise were the major barriers to the effective implementation of Internet Marketing strategies and operations, and that training of managers and employees could considerably contribute to their marketing success. Managers expressed their interest in the provision of a web-based training system to aid their learning and knowledge acquisition.

Exploring the possibility of using case based reasoning to enhance training and learning, the survey asked "in what way would you prefer to learn about Internet Marketing?". 40\% of respondents selected "presentation of case studies", and 54\% selected "model Internet solutions". This evidence indicates the willingness of SMEs manager to learn from other businesses' previous experience and lessons, and shed light on adopting CBR approach in the project.

\section{ARCHITECTURE OF TRIMAR SYSTEM}

In responding to SMEs training and decision support needs, one of the major outcomes of TRIMAR project was the provision of a web-based intelligent training and support system using case based approach. The general architecture of the system is shown in figure 1 which consists of three major modules:

a) Self Assessment Tool (SAT).

b) Training Modules (TM).

c) Case Retrieval System (CRS).

Self Assessment Tool (SAT) - Since one of the basic elements of learning is control and self-assessment of knowledge and skills, SAT module was designed to assess the knowledge of users in the field of Internet marketing. The SAT module provides access to on-line tests, facilitates passing subsequent stages of the training and enables tracking, managing and reporting users self-assessment process and results. Webbased training has potential to provide users with personalised training materials, but first of all, preliminary determination of their levels of knowledge on any selected topic should be obtained. This enables the system to direct users to an appropriate lesson at an appropriate level. That is what SAT is responsible for within the TRIMAR system.

Training Modules (TM) - The basic function of TM is to provide SMEs with theoretical and practical knowledge that refers to introduction and utilisation of Internet marketing in business. Two levels of training are 
developed: basic and advanced levels. At the basic level, training is presented as a form of themed lessons. that correspond to the needs identified by SMEs in TRIMAR surveys.

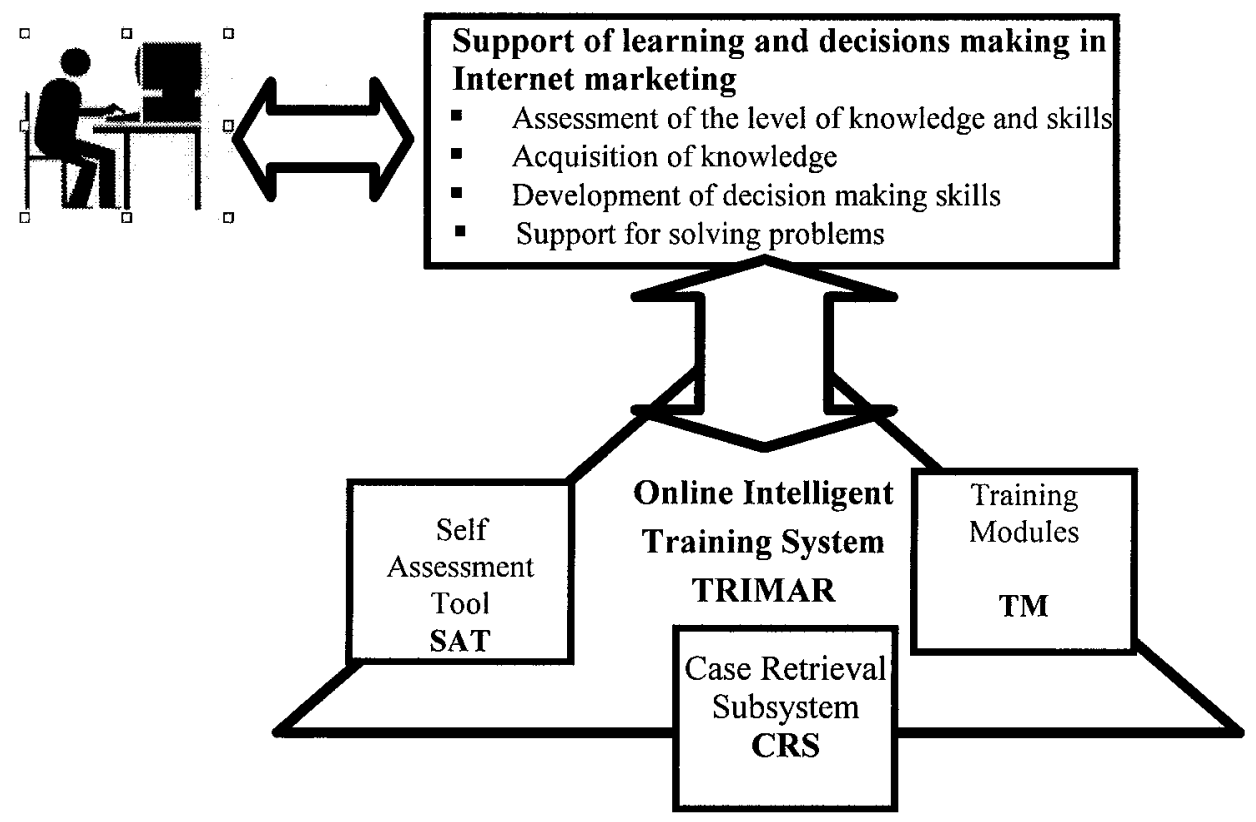

Figure. 1. Architecture of TRIMAR system

Advanced level comprises cases studies that allow for implementation of the case-based learning method and constitute practical examples of performing Internet marketing activities by enterprises. The aim of the case studies is to develop decision-making skills and to solve problems by reviewing appropriate cases. Case studies were developed in cooperation with SMEs that have already acquired experience in implementing and maintaining Internet marketing activities. Such co-operation includes those undertakings that were successful as well as those that failed. Each case study describes problems of SMEs in reference to three levels of management: strategic, tactical and operational. Each case study is summarised in a form of a "Case Study Report" and "Case Study Analysis".

Case Retrieval System (CRS) - CRS serves as a learning tool as well as a decision support subsystem. It contains 70 cases and incorporates case searching and matching activities underpinned by case based reasoning method. More details about this module are provided in the following sections. 


\section{DEVELOPMENT OF CRS SUBSYSTEM}

Case Retrieval Subsystem aims to facilitate and enhance knowledge acquisition and learning by providing with relevant cases collected during TRIMAR project. The case retrieval is inferred from the case based reasoning technique. Case-based reasoning is one approach in the development of knowledge-based systems that is able to retrieve and reuse solutions that have worked for similar situations in the past (Sporl et al, 1999). A particular strength of CBR over most other methods is its inherent combination of problem solving with sustained learning through problem solving experience (Choy and Lee 2000). A case is therefore a contextualised piece of knowledge representing an experience. It contains two major parts: the lesson it teaches - the case抯 content, and the context in which it can teach its lesson - its indexes (Kolodner, 1993).

CBR technology has been successfully exploited in different application problems ranging from help desk applications, to planning and design (Choy and Lee, 2000, Choy et al., 2004; Mclvor and Humphreys, 2000). Applying CBR to a particular application problem requires identification of parameters relevant for decision making, acquiring cases that are described according to these parameters and maintaining the quality of the case-base over time.

Developing effective Internet marketing strategies and methods for competitive advantages in SMEs involves in making various decisions at operational, tactical and strategic levels. Empirical evidence collected from TRIMAR project indicates that when small business managers engaged in their learning and decision making activities on adopting the Internet marketing strategies and techniques, they would like to learn the lessons and experiences from other companies involved in similar situations. This evidence forms a strong base for adopting CBR approach in TRIMAR.

The initial stage of development was to review and to test known commercial CBR systems in order to ascertain their applicability for the intended TRIMAR project. The criteria used were that they had to be consistent with the way that cases were represented in the marketing domain, use some form of algorithmic search (such as nearest neighbour), be web enabled and to be within the budget of the project. A decision was made to use a bespoke system using a propriety database, Microsoft Access (C). This was able to represent cases effectively within the existing data structure, it was able to be accessed through a browser interface, and algorithmic search could be imbedded within the application and used to find the nearest matching cases. 


\subsection{Selection of Case Indexes}

The critical part of any CBR system lies in the cases it possesses. Based on the domain knowledge of marketing and Internet marketing, a template was deigned for collecting and recording cases in five participating countries in the project. The template serves a base for the selection of indexes in the case base.

One of the major concerns with CBR is that of accurate case retrieval In order to facilitate this case retrieval, cases in the case library are assigned indexes. How efficient and successful the case retrieval is, depends mostly on choosing appropriate indexes to guide search for relevant cases in the case library. Good indexes should be truly relevant and generalised, but not over-generalised (Barletta \& Mark, 1988).

The selection of the indexes in TRIMAR involved the collection of a small number of marketing cases from SMEs within the EU. This was achieved by providing these companies with a pro-forma with which to record past cases of a particular problem, the resolved solution to that problem and other aspects relating to the company's strategic, tactical and operational procedures. Initially, 10 cases were selected in order to analyse for appropriate case index fields. The analysis provided 7 initial fields which seem to provide the most appropriate description of the problems and their associated solutions. On the basis of the first findings, the pro-forma was modified in accordance with the selected index fields and distributed to a larger number of SMEs. There were 60 new cases returned for analysis, and from these, another 2 index fields were added to the initial 7 . This made 9 index fields in total, which seemed to adequately reflect the general indexing for the system. The selected indexing fields are shown in table 1 .

Table 1. Case indexing fields

\begin{tabular}{|l|l|}
\hline Indexing Fields & \multicolumn{1}{|c|}{ Content } \\
\hline Company Category & $\begin{array}{l}\text { The business function of the company. These were } \\
\text { identified as different category groups. A company's } \\
\text { business function would fall into one of these groups. }\end{array}$ \\
\hline Problem Category & $\begin{array}{l}\text { The problems the various companies seem to be } \\
\text { experiencing. These were identified as different category } \\
\text { groups. A company's problem would fall into one of these } \\
\text { groups. }\end{array}$ \\
\hline Business Strategy & $\begin{array}{l}\text { The level of business strategy, as in the use of business } \\
\text { models and planning, that a company was using for general } \\
\text { business activities }\end{array}$ \\
\hline Company Size & $\begin{array}{l}\text { The size of the company as the number of employees } \\
\text { employed }\end{array}$ \\
\hline Website Strategy & $\begin{array}{l}\text { The level of website strategy, as in website planning, that a } \\
\text { company was using for the development and presentation of } \\
\text { their website }\end{array}$ \\
\hline IT Knowledge & The level of IT knowledge a company has at its disposal \\
\hline
\end{tabular}




\begin{tabular}{|l|l|}
\hline Market Reach & The market in which the company was active \\
\hline $\begin{array}{l}\text { Management } \\
\text { Structure }\end{array}$ & $\begin{array}{l}\text { The type of management structure that exists within a } \\
\text { company }\end{array}$ \\
\hline Corporate Identity & The level of company visibility within its trading sector. \\
\hline
\end{tabular}

\subsection{System Structure, Retrieval and Retention}

The efficiency of case retrieval not only depends on the appropriately selected indexes, but also the chosen organisational structure of the case memory and the retrieval algorithms used.

In general, a case memory can be organised either sequentially (flat memory) or hierarchically. In a flat memory, cases are stored in a simple list. Hierarchical organisation involves clustering of cases in certain categories. Thus, hierarchical structures cluster together cases that share a number of features, where clustering has a priority over the discrimination of cases.

The retrieval algorithm relies on the indexes and the organisation of the memory to direct the search of potentially useful cases. Some of the wellknown methods for case retrieval are: nearest neighbour, induction, knowledge guided induction and template retrieval (Watson, 1997).

The case memory in TRIMAR was organised as combined hierarchical and sequential structure. One level of hierarchy was employed in order to cluster the company categories, this being based on the assumption that a user would be more interested in accessing problems within their own business function. The system then employed a sequential structure for cases falling under each company category. This is shown in Figure 2.

Although the main method for retrieval was based upon clustered company categories, other options were provided to access similar problems under different company categories or to provide a search for different problems under similar company categories.

The retrieval mechanism was provided by a weighted, nearest neighbour type algorithm as shown in (1) (Kolodner, 1993), as this would allow cases to reside in unique regions of the case-space, thus providing a more accurate retrieval system.

$$
\operatorname{Similarity}(T, C)=\sum_{i=1}^{n} f\left(T_{i}, C_{i}\right) \times W_{i}
$$

The weightings were provided by analysis of the case studies available, this being based upon the collective, relative importance companies seem to place upon the various case fields. The nearest-neighbour search algorithms 
were implemented using VB and SQL routines embedded within the casebased data structure. The system provided the following functions for users:

- Add New Cases - to add new cases to the system.

- Review Cases - to view all the cases in the case base.

- Find the Nearest Case - to find cases that matched their problem.

These functions were provided through a browser interface, where the index fields were shown to the user via a set of drop-down menu (figure 3).

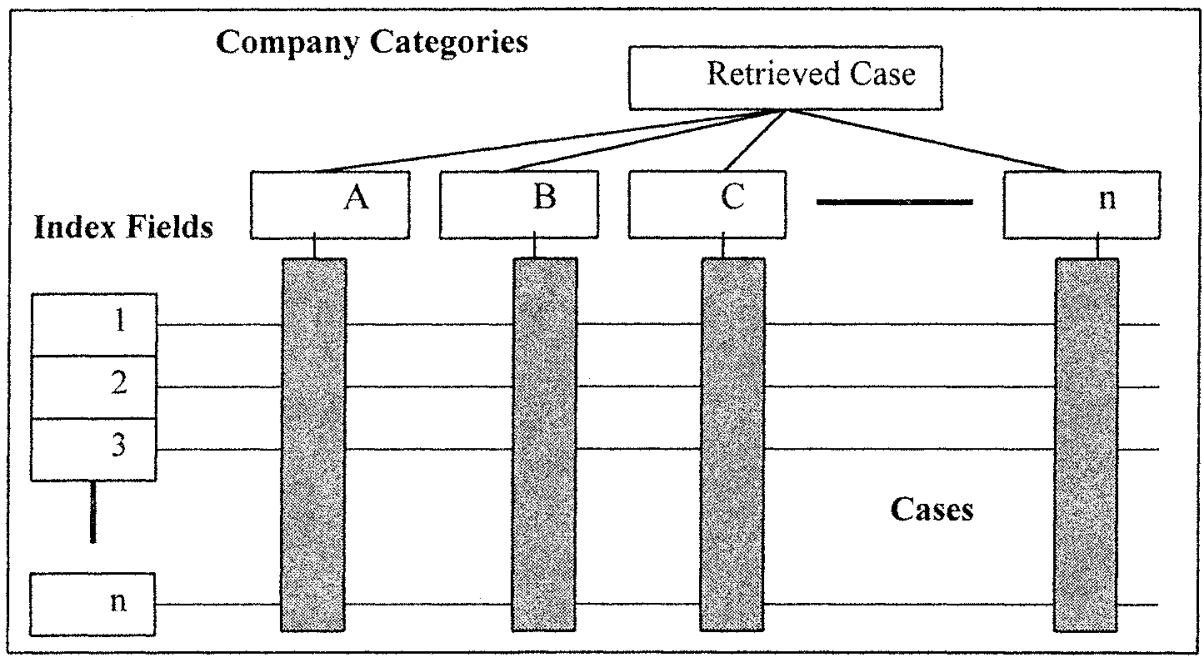

Figure 2. Case Memory Structure

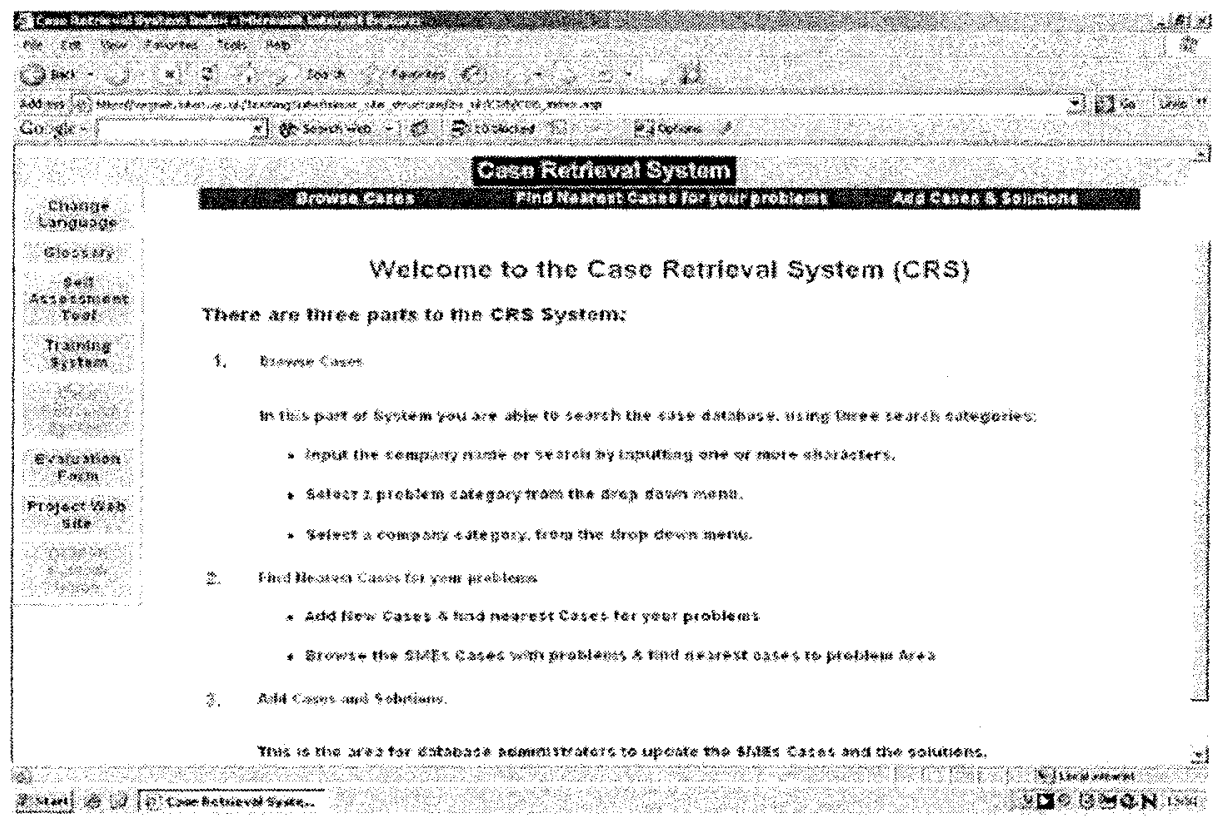

Figure 3. CRS browser interface 
The result of the nearest neighbour search returned relevant case solutions, ranked in order of importance. The closest problem match being the most important. The solutions were presented in the form of a text solution and, if required, a full strategic, tactical and operational analysis associated with that solution.

A secondary data structure was used to capture each user担 interaction with the system. The information retained in this data structure included a text description of the problem, together with related index fields, as provided. This information was retained in this data structure until the user provided a unique solution to their problem. A Null Adaptation technique (Watson, 1997) was used to provide the solution space for the new cases. These cases were then added to main case-based structure, thus providing additional cases for the system.

These functions were provided through a browser interface, where the index fields were shown to the user via a set of drop-down menus. The CRS Module collects knowledge acquired through the analysis of case studies. The module provides the basis for analysis of experiences (successes and failures) of SMEs in Internet marketing. Such experiences are extremely valuable for those companies that are now at the stage of implementing Internet marketing. CBR approach allows for resolving decision-making problems through adaptation of solutions that were implemented by other companies.

\section{DISCUSSION AND CONCLUSION}

TRIMAR system attempted to combine traditional way of delivering text-based learning materials with a case base to enhance knowledge acquisition and transfer. The strength of the system is its case base and the use of CBR. The case base serves two purposes in the system: 1. to help SMEs managers to learn theories and concepts with relevant case studies; and 2. to support the Internet marketing decision making by providing solutions from similar cases. TRIMAR system was tested and evaluated by various users via an online evaluation questionnaire. The feedback was positive and encouraging. For example, some users said:

"The system offers the possibility for an integrated theoretical and practical learning for companies."

"The examples shown in the case studies allow the user to find solutions for potential business problems without having to experience them. Problems 
concerning cultural and social differentiation are evident through the case studies and solutions for the problems that are supplied."

However, the system担 power, especially its capability to find solutions for existing problems is limited by its small case base. This was noted by some users, e.g.

"The idea of the system is very good - especially the case base. But at the moment the volume of the case base is too small to find matching problems. I hope that many SMEs will put in their cases so the case base will grow."

It is hoped that with the "add new cases" function provided in TRIMAR the case base can be extend to provide better services to SMEs.

\section{ACKNOWEDGEMENT}

The authors would like to acknowledge the project partners for their cooperation and contribution to the project. They are University of Munster; Karol Adamiecki University of Economics; Universidade Alberta, South Bank University, Technical University of Kosice .

\section{REFERENCES}

Barletta, R. and Mark, W. Explanation-based indexing of cases In Proceedings of the Seventh National Conference on Artificial Intelligence, California, (1988), AAAI Press.

Chaffey D. E-business and E-commerce Management, Strategy, Implementation and Practice Pearson Education Limited, Edinburgh Gate. (2002).

Choy, K.L. and Lee, W.B. Task allocation using case-based reasoning for distributed manufacturing systems. Logistic Information Management, 13 (3), (2000), 167-176.

Choy, K.L.; Lee, W.B. and Lo, V., An enterprise collaborative management system - a cse study of supplier relationship management. The Journal Of Enterise Information Management. 17(3), (2004), 191-207.

Coupey E. Marketing and the Internet, Prentice-Hall, New Jersey, (2001).

Dann S. Strategic Internet Marketing, John Wiley \& Sons. (2001).

Kolodner J.A Case-Based View of Case-Based Reasoning: What Have We Wrought? College of Computing, Georgia Institute of Technology, Atlanta, (1997).

Kolodner J. Case-Based Reasoning, Morgan Kaufmann Publishers, San Francisco, (1993).

Mclvor, R.T. and Humphreys, P.K. A case-based reasoning approach to the make or buy decision. Integrated Manufacturing Systems, 11(5), (2000). 295-310.

Sporl,B.B., Lenz, M. and Hubner, A. Case-based reasoning - A survey and future directions In: Puppe, P. (Ed.) Proceedings of the 5th Biannual German Conference on Knowledge Based Systems, W默詹zburg, Germany, (1999).

Watson I. Applying Case-Based Reasoning: Techniques for Enterprise Systems, Morgan Kaufman Publishers, San Francisco, (1997). 